ARTICLE

https://doi.org/10.1057/s41599-019-0284-z

\title{
What makes the difference? An empirical comparison of critical aspects identified in phenomenographic and variation theory analyses
}

\author{
Mona Holmqvist (iD ${ }^{1} \&$ Per Selin ${ }^{2}$
}

\begin{abstract}
This study investigated differences and similarities in outcomes of analyses based on phenomenography and variation theory. We used the same data for both analyses to highlight the assumptions of each approach. Participants were 198 students (grades 7-9) who provided written answers to the question 'What is learning?'. The phenomenographic analysis identified qualitatively different categories representing different ways participants' conceptualised learning, separated by critical aspects that distinguished each category. This analysis found six categories, seeing learning as: extended skills, process, investment, feelings, object-knowledge, relationships, and feelings. The variation theory analysis identified aspects constituting the object of learning, with critical aspects being those not yet discerned by the learner. Aspects and features identified in this analysis were: learner (skills, abilities, pre-knowledge, attitudes), learning activities (brain, listen, repeat, practicing), learning source (teacher, school, learning materials, friends, Internet, places/persons outside school), content/object of learning (facts, information, activity), and outcomes (job, enhanced future, development, performance, widening knowledge). Aspects and features not yet discerned are critical, and must be made discernable for the learner to enhance their understanding. This use of critical aspects differs from phenomenography, in which critical aspects identified qualitatively different ways of seeing learning (i.e., categories of collective experiences). In variation theory, aspects (dimensions) and features (values of the dimension) relate to individuals' understanding in specific contexts (e.g., a school class). A major difference between phenomenography and variation theory is the perspective of collective- and individual-expressed discernments. In phenomenography, a person may belong to several categories, whereas in variation theory, the aspects an individual has discerned reflect the way that person understands the phenomenon. This means the outcome of variation theory can be used to design and test the outcome of instruction, whereas the outcome of phenomenography provides information about general assumptions of how a phenomenon can be discerned.
\end{abstract}

\footnotetext{
${ }^{1}$ Faculty of Learning and Society, Malmö University, SE-205 06 Malmö, Sweden. ${ }^{2}$ City of Borås, SE-501 80 Borås, Sweden. Correspondence and requests for materials should be addressed to M.H. (email: mona.holmqvist@mau.se)
} 


\section{Introduction}

henomenography was developed in the 1980s as a qualitative research approach in education, and focuses on how people experience the same phenomenon differently (Marton, 1981).

These experiences are shaped by 'pools of meanings' distinguished by critical aspects. Based on findings from phenomenographic research, variation theory (a theory of learning) was established in 1997. The main assumption of variation theory is that learning requires simultaneous variation to discern aspects that comprise a phenomenon (Marton, 2014). These aspects become critical if they are not yet discerned by the learner. To improve understanding of the different conceptualisations of 'critical aspects' in these two approaches, this article demonstrated how the concept 'critical aspects' is used differently in phenomenography and variation theory. No such study has previously been reported. Previous studies have compared the two approaches. For example, Pang (2003) discussed the first and second phases of variation, which explains how phenomenography uses variation to describe differences in how a phenomenon can be discerned. Pang argued that the second phase of variation is based on the assumption that the learner discerns variations in aspects of the phenomenon. However, that study and more recent research by Pang and Ki (2016) were theoretical discussions and not based on empirical studies. Pang and Ki (2016) explained the different conceptualisation of critical aspects as:

Phenomenographic studies have brought critical aspects to prominence as specific and important features of the outcome space that distinguish qualitatively different ways of experiencing or seeing a phenomenon (Collier-Reed and Ingerman, 2013).[...] In the variation theory of learning, in contrast, a critical aspect is more theoretically grounded, and taken as synonymous with a dimension of variation, while 'critical features' are seen as the target values of critical aspects or dimensions of variation. (Pang and Ki, 2016, p. 324)

Lo (2012) explained the difference between aspects and features as: 'Critical aspect refers to a dimension of variation, whereas critical feature is a value of that dimension of variation' (Lo, 2012, p. 65). Another article that discussed the development of variation theory (Åkerlind, 2015) included an empirical study of students' learning in higher education; however, differences in the use of critical aspects between the two approaches were not specifically discussed. Åkerlind (2015) defined critical aspects from a phenomenographic perspective as related to shaping collective pools of meanings in categories separated from students' individual discernments.

In the present study, the understanding of variation theory is based on the development of this research approach in Sweden (Marton and Booth, 1997; Marton, 2014). As students in a class differ, an assumption of variation theory is that critical, relevant, and irrelevant aspects and their features have to be identified for each individual to understand how knowledge of a specific object of learning can be developed (Holmqvist et al., 2008; Marton, 2014; Pang and Ki, 2016; Runesson 1999). Irrelevant critical aspects are aspects that do not appear of relevance for knowledge development (or may even hinder the learner developing their knowledge). Identifying irrelevant critical aspects is not captured in a phenomenographic approach (Pang and Ki, 2016). An example of an irrelevant aspect is the understanding of how the plural form of a noun is usually formed by the addition of an ' $s$ ' when learning genitive case. This irrelevant aspect becomes critical for learners with difficulties; for example, to separate 'girls' from 'girl's'. Here, the apostrophe becomes a critical feature, which is a discernment that is difficult to capture in a ssphenomenographic analysis.
To contribute to understanding of the different ways critical aspects are used in each approach, we analysed the way in which the same data revealed different outcomes (critical aspects) depending on whether phenomenography or variation theory was used. We used students' expressed understanding of the concept 'learning' as the data for both analyses. We chose this concept because the Swedish school curriculum guidelines indicate that teachers should assume students can and want to take personal responsibility for their own learning and work in school (The Swedish National Agency for Education, 2018).

Although phenomenography and variation theory have similarities (e.g., ontological and epistemological standpoints) the approaches can be used independently of each other. Phenomenography is a research approach developed by Marton (1981), which focuses on how different people experience the same phenomenon. Interviews or written text may be used as data reflecting participants' discernments. These data are categorised into different pools of meanings qualitatively separated from each other by distinguishing critical aspects. A key aspect is the nature, quality, or character of the phenomenon/object under focus, or the component parts that make sense of the entirety when considered together. The results of a phenomenographic analysis describe categories that represent how people experience the same phenomena differently.

Variation theory was developed as a learning theory and includes assumptions about predicting how critical aspects and critical features can be made discernable so students can obtain deeper knowledge (Marton, 2014). Variation theory was developed by Lo and Marton (2011) and has strong connections to Chinese learning theories ( $\mathrm{Gu}$ et al., 2004). Based on the phenomenographic tradition, the development of variation theory aimed to theorise teaching and learning, rather than explore qualitatively different ways the same phenomena can be experienced (Lo, 2012). Variation theory is used to guide research in education and understand students' approaches to learning (Holmqvist et al., 2008). Development of variation theory resulted in a widening of the research tradition, although contradictions within the research community have sometimes resulted in a perception of fragmentation of this approach. Åkerlind (2017) stated, '...phenomenography is much better known and more widely distributed geographically than variation theory, as you would expect given its longer history (40 versus 20 years)' (p. 9).

As a research approach, phenomenography has been in use for around twice as long as variation theory; however, the rapid dissemination of published studies using variation theory is promising. A search of the ERIC EBSCO database resulted in 89 hits for 'variation theory' and 174 hits for 'phenomenography'. The close relationship between the two approaches means that the common research field is expanding. For example, use of variation theory to find critical aspects to theoretically understand how to develop new knowledge in specific areas, combined with general knowledge about categories of different conceptualisations of the same phenomenon (phenomenography) may offer a richer picture of meaning-making and learning.

In phenomenography, a 'conception' is the unit of description (Marton and Booth, 1997; Marton and Pong, 2007), which represents an abstract idea or mental symbol of a limited part of the world that makes it distinguishable from other parts. A phenomenographic analysis focuses on referential (placement in an ambient context) and structural (features that constitute the phenomenon) aspects of a phenomenon. In this study, we analysed students' descriptions of what learning is. It is important to note that the phenomenon (learning) itself was not the focus of this study, but rather was used as an example to 
highlight differences in outcomes from the analyses using the two approaches (phenomenography and variation theory). The distinction between phenomenography and variation theory lies in separating the structural dimension between conceptions and the internal structure within an object. Traditionally, phenomenography focuses on the differences between collectively shaped categories of individuals' conceptions of the same phenomenon. In contrast, variation theory focuses on the internal structure of an object (e.g., learning) discerned by the learner, as well as the typical or discipline-specific way of seeing the object. Variation theory seeks to find aspects and features that shape the phenomenon, some of which are critical (necessary to discern) to build understanding of the phenomenon. Both variation theory and phenomenography are related to the collective understanding of the phenomenon and search for common aspects and features that are critical (Marton and Booth, 1997). Individual learners focus on different aspects in variation, not all of which are necessary to understand the phenomenon in a more meaningful way. In this study, the dual focus was on how students regarded the same phenomenon differently, and the aspects and features constituting the phenomenon that made discernment possible. We discussed the way in which the same data showed different outcomes (critical aspects) depending on the approach used. The concept under study (students' expressions about what learning is), was previously studied by Duarte (2007).

Marton et al. (1993) proposed a system of six conceptions in two groups (quantitative and qualitative) that defined learning: increasing knowledge, memorising and reproducing, applying, understanding, seeing things in a different way, and changing as a person. However, Duarte (2007) studied students' conceptions using a questionnaire and factor analysis, and found more conceptions than reported by Marton et al. (1993), including a new conception: understanding and applying. In this study, we used a free-text question to collect data (students' expressions of what learning is), and compared the outcomes of a variation theorybased analysis with those of a phenomenographic analysis. This represented a departure from the different conceptions of critical aspects in these two perspectives.

Although phenomenography has traditionally been used as a research approach in higher education (Prosser and Trigwell, 1997), it has been developed and transformed for use in different contexts. A question has also been raised as to whether phenomenography has transcended into variation theory (Bowden, 2006). We suggest that the two approaches are unique, but complementary. The approaches can benefit each other and strengthen the overall research approach, as they differ slightly in focus. Phenomenography defines pools of meaning for a phenomenon in a descriptive way, whereas variation theory studies necessary conditions for learning in a more prescriptive way. Both approaches focus on a phenomenon as either an observable object or an abstract phenomenon that can be defined. Phenomenography focuses on the experience of the phenomenon of others (a second-order perspective), whereas variation theory also focus on the phenomenon itself (a first-order perspective). When merging the phenomenon with the learner, or the collective and individual perspectives, both first- and second-order perspectives are used simultaneously.

\section{Distinction of critical aspects}

Phenomenography and variation theory refer to critical aspects on slightly different grounds. Regarding phenomenography, Collier-Reed and Ingerman (2013) said:

From within the pool of meaning, meaning units are read in the context of all those that have come before, and in the context of the interviews from where they have been derived. Each meaning unit informs and helps delineate the others. Critical aspects are identified, and these help to recognise themes that run through the data. (p. 253)

The phenomenographic approach considers 'meaning units of experience', with these units of experience differentiated from the individuals who experience them. The results are presented as qualitatively different categories of meaning-making for the same phenomenon. From a phenomenographic perspective, critical aspects refer to features used to qualitatively distinguish categories from each other. The outcome of such an analysis can be used in education, but must be reformulated for use (e.g., by teachers in teaching), as the approach is mainly descriptive and does not aim to develop practice.

Variation theory defines critical aspects as aspects that must be discerned by a learner to develop understanding of an object of learning; these aspects are critical for understanding the phenomenon in a more developed way, but are yet to be discerned by the learner (Marton, 2014). Critical aspects are found in the relationship between the learner and the phenomenon that is to be learned, merging a first-order perspective (teachers' way of discerning the aspects of the phenomenon/object of learning) with the experiences of the learner. In this case, the first-order perspective refers to a 'typical', discipline-grounded conceptualisation shared by the majority of individuals in a group, although it might not be typical for the students. An 'atypical' conceptualisation is an alternative conceptualisation, which may be labelled a misconception in other scientific approaches (Vosniadou, 2009).

The results of analyses from both phenomenographic and variation theory perspectives may contribute to our understanding of what it takes to learn, and offer insights about how students learn in a learning situation. Teachers could use this information when teaching. The assumptions of variation theory about learning (e.g., that a person has to experience variation in different aspects of an object of learning simultaneously to learn) may be tested in interventions.

An object has many aspects, and not all aspects are critical; thus students who fail to learn may be focusing on aspects other than the critical aspects. Alternatively, they may not be focusing simultaneously on all critical aspects and their interrelationships, which is required to acquire the way of seeing the object intended by the teacher (Lo et al., 2005, p. 19-20). Thus, when teaching, we should take as our point of departure what is to be learned (i.e., object of learning). For every object of learning and for every learner there are critical features that the learners must be able to discern; critical features are critical because the learners participating in the study have problems with them, and different learners may have different kinds of problems. (Lo and Marton, 2011, p. 9)

As variation theory refers to the object of learning instead of pools of meaning, the focus is on the merged meaning-making between the learner and the content learned. A critical aspect (and its features) therefore reflects an aspect pertaining to the phenomenon/object of learning that has not yet been discerned by the learner. As a learning theory, variation theory strives to describe, explain, and predict requirements for learning.

Discerning the object of learning amounts to discerning its critical aspects. To discern an aspect, the learner must experience potential alternatives, that is, variation in a dimension corresponding to that aspect, against the background of invariance in other aspects of the same object of learning. (Marton and Pang, 2006, p. 203) 
In a teaching situation, critical aspects must be related to the object of learning addressed in that specific situation. Pang and Ki (2016) argued that the phenomenographic notion of critical aspects is independent of an individual's identification of these aspects. The variation theory perspective that critical aspects are found in the relationship between learner and object is both valid and important for teachers. In variation theory, critical aspects are dynamic, and the patterns of variation and invariance are critical for students' learning.

Correspondingly, the critical aspects that empower learners to distinguish the discipline-grounded way of seeing from the alternative ways of seeing they bring to the classroom can be identified. Targeting these critical aspects, a pattern of variation and invariance can then be co-constituted by the teacher and learners in the learning environment. In this way, both teachers and learners can be helped to distinguish differences and reflect on their own understandings. (Pang and Ki, 2016, p. 328)

Pang and Marton's (2005) study of economic concepts showed how phenomenographic analyses can be an initial step in an intervention based on variation theory. In that study, the object of learning was 'the ability to account for change in the market price of a commodity by taking into consideration the relative magnitude of change in its demand and supply' (Pang and Marton, 2005 , p. 160). Initially, those authors collected and qualitatively analysed students' answers to specific questions. They found five categories: (A) change in features of the good; (B) change in demand only; (C) change in supply only; (D) change in both demand and supply (without comparing their magnitude of change); and (E) change in both demand and supply (taking into account the relative magnitudes of change). Students were asked why the price of chickens did not increase when the government killed 1.2 million chickens. Their answers were distributed in different categories and compared before and after the intervention to illuminate qualitative differences. That study argued: 'In summary, to develop an economic way of understanding how the price of a commodity will change as a result of a simultaneous change in its demand and supply, one must focus on and discern the critical aspect of the object of learning, the relative magnitude of simultaneous changes in demand and supply' (Pang and Marton, 2005, p. 162). To summarise, the identified categories represented levels of understanding, distinctly separated by critical aspects. However, the critical aspect that enhanced students' learning was the relative magnitude of simultaneous changes in demand and supply.

In the present study, we focused on the different ways critical aspects are used by phenomenography and variation theory when analysing the same empirical data. Data were generated from the experience of the concept of 'learning' as expressed by secondary school students. Our results described the different outcomes (critical aspects) from the two analyses, and showed how the different approaches can be understood and complement each other.

\section{Implementation of the study}

Methods. Traditionally, phenomenography uses interviews to gather information about people's conceptions of the same phenomenon (Åkerlind, 2012). Interviews have various advantages as a data collection method; for example, the interviewer's understanding of the respondent's conceptualising can be elaborated during the interview. Disadvantages of interviews include the risk of bias and possible influence of the interviewer in a certain direction during the interview (Merriam and Tisdell, 2015). In this study, we used short written answers to one question. This meant that the data lacked the richness of information possible from transcribed interview data. However, participants were not influenced by the researcher to answer in a certain direction. One researcher (the second author) was present when participating students answered the question. A limitation of collecting data via a written response to a single question is the phenomenon (learning) itself. As participants may have different understandings of the concept or make sense of it differently, their responses may not reflect the same phenomenon. Data saturation was reached in this study, as we used a group of participants chosen from one school with data collected at the same time. In addition, we used multiple classes from the school. We assumed that participants shared the same phenomenon as they shared the same context and teachers (albeit in ten different classes).

Ethical considerations. Informed consent was given by all participants (students aged 13-16 years) before the study. They were informed that answering the question was voluntary, and that their answers would be used for research purposes. By answering the questionnaire, they gave their consent to include their anonymous answers to the data analysis. They were instructed not to sign their answer paper or provide identifying information. The quotes included in this paper were translated into English by the authors.

Participants. Participants in this study were students $(n=198)$ from grades 7-9 (aged 13-16 years) at a single secondary school. The school is situated on the outskirts of a city in Sweden. Most students were from three schools in two nearby villages or the area where the secondary school is situated. Approximately $65 \%$ of teachers at the selected school were qualified to teach the subjects and age groups they taught. This was close to the average percentage for both the city and the country, because the shortage of teachers means teachers are often qualified in subjects other than those they teach. Almost all students at the school had Swedish as their native language, and $<5 \%$ spoke Swedish as their second language. The data used in the analyses comprised written answers to the study question (Table 1). The classes that participated in this study were those where the teachers considered participation appropriate according to the students' workload at the time of the study.

Analysis. Written answers for one question were used as the unit of analysis. All students were asked 'What is learning?' (in Swedish: Vad är lärande?). The question was put to students via a presentation document shown in a lesson. All participants saw an identical document. If any individual needed more information about the concept 'learning', the question was rephrased, but the meaning was the same; for example, asking the student to

\begin{tabular}{|lll|}
\hline \multicolumn{2}{l}{ Table 1 Participants and non-responders from each class } \\
Class & Participants & Non-responders \\
\hline $7 a$ & 22 & 2 \\
$7 b$ & 24 & 0 \\
$7 c$ & 23 & 0 \\
$7 \mathrm{e}$ & 19 & 1 \\
$8 \mathrm{a}$ & 25 & 0 \\
$8 \mathrm{~b}$ & 19 & 3 \\
$8 \mathrm{e}$ & 22 & 0 \\
$8 f$ & 6 & 16 \\
$9 \mathrm{a}$ & 18 & 0 \\
$9 \mathrm{c}$ & 20 & 0 \\
& 198 & 22 \\
\hline
\end{tabular}


describe what is meant when we say someone learns. All participating students received the same information. The answers were written on paper in Swedish.

The same data were used for two different analyses, one based on a phenomenographic approach (Marton et al., 2005) and one based on variation theory (Ling Lo, 2012; Marton, 2014). The second author collected the data and the first author performed both analyses. All answers were transcribed and sorted in tables. The first step was the phenomenographic analysis. Participants' written answers were manually analysed several times to find qualitatively different pools of meanings. This analysis revealed groups of qualitatively different categories with critical aspects (aspects that distinguished categories from each other). The material was then reread several times to find similarities and differences between the expressions. This analysis separated the expressions from the people who expressed them.

During the phenomenographic analysis, qualitatively different pool of meanings in the students' expressions of learning were searched for in the data; these expressions related to each other in a distinct way different from other expressions. The pools of meanings were marked with different colours, and each time a new way of expressing what learning is emerged, a new colour was used. Next, aspects that were critical for distinguishing the categories were identified. In total, six categories were found, and hierarchically arranged from the most developed to the least developed. Participants' written expressions could be distributed in several different categories, as an excerpt from an individual may contain several different expressed understandings.

After the phenomenographic analysis, the data were analysed again using variation theory. The aspects and features of the phenomenon mentioned by students were analysed to determine aspects that had been discerned and those that had not yet been discerned. We focused on the dimensions of variation students expressed, and aspects and features found in the empirical material. Theoretically, if a student had discerned some aspects, other aspects might be critical to develop further knowledge. Similarly, a typical understanding of what learning is implies discernment of some common aspects of learning. If these aspects are not discerned by the learner, they are critical. In an interventional study, further learning could be predicted by making these critical aspects (not yet discerned) discernable for students.

The phenomenographic analysis yielded descriptive results that showed how different students experienced the same phenomenon differently, with critical aspects separating pools of meaning. The variation theory-based analysis identified aspects and features that were critical for a more developed understanding of the phenomenon. The data were analysed to organise aspects discerned, and dimensions features within that aspect. In this case, the typical way of seeing learning was not analysed in relation to teachers' typical understanding. Instead, critical and irrelevant aspects were described from the dimensions of variation found in the empirical material. This analysis revealed five aspects and dimensions of features, which became critical for developing knowledge about learning if they were not discerned. Three features were found to be irrelevant for understanding what learning is. In a learning situation, students' meta-cognition (i.e., thinking about thinking) regarding their own learning strategies could be developed based on this analysis (Boström and Lassen, 2006).

\section{Results}

The results of the phenomenographic analysis are presented first, followed by those from the variation theory-based analysis. The phenomenographic analysis revealed pools of meanings of how differently 'learning' was conceptualised and categorised by participants, with a focus on the critical aspects that defined the differences between the categories (Collier-Reed and Ingerman, 2013). The variation theory analysis clarified aspects and features that comprised the delimited phenomenon 'learning' based on participants' expressions, and how it was/could be structured differently depending on the individual (Ling Lo, 2012; Marton, 2014).

Phenomenographic analysis. The phenomenographic analysis revealed six qualitatively differentiated categories, presented in a hierarchical order (A-F) (Table 2). In this hierarchical order, the lower level categories were included in the higher-order categories. For each category, the critical aspect represented the threshold necessary to enter a new category. For example, the critical aspect that distinguished the seeing learning as 'Attributes' and 'Simple casual relationship' categories reflected the focus of the phenomenon 'learning'. 'Attributes' focused on learning as an expressed feeling, whereas 'Simple casual relationships' focused on a single component necessary to learn or tools for learning that make learning possible. The critical aspect between this category and the next (more developed) 'Object' category was the focus on knowledge, rather than a tool to use. The object 'knowledge' was experienced as something concrete or already found by someone else, which had to be handed over or mastered by the learner. The next step in the hierarchy was the 'Investment' category. The critical aspect differentiating this from the previous category was seeing knowledge as an object that can be used on future occasions (e.g., to get a good job or master later challenges). This led to the next category, 'Process', where participants' described the process needed to make learning of certain knowledge possible to master and use in other situations. Finally, the sixth category was 'Extended skills', in which participants' defined learning as something that changes you as a person in terms of being able to perform, behave, act, and think in new ways that were not possible before. The critical aspect between the two highest-order categories lay in seeing neither process nor knowledge as an object; instead, the focus was on a personal development regardless of content or process.

Analysis based on variation theory. The analysis based on variation theory highlighted the dimensions of variation regarding the aspects and features that comprised 'learning'. A perspective of 'changes' was central in this analysis, described by using contrasts, such as understanding things you have not previously understood (extended knowledge) and different ways to perform (developed skills). The referential perspective was described by participants highlighting things such as: where learning may happen (environmental perspective), what competencies an individual has to have to make learning happen (individual perspective), from whom it is possible to learn (relational perspective), what has to be learned (content perspective), what a person who wants to learn has to do (activity perspective), and changes that are due to learning (transformative perspective).

Table 3 presents the dimensions found in the analysis, or aspects and their features expressed by participants. The results showed the dimensions of variation in participants' answers, which were based on aspects and their features identified in the data. Although the analysis provided an overview of the identified aspects, a phenomenon may also include aspects and features that were not found in the data but that are important for understanding the phenomenon in a more developed way. The analysis in this case only considered the dimensions opened up by participants' expressed conceptions. Variation theory also considers first-order perspectives of the phenomenon/object of 


\begin{tabular}{|c|c|c|c|}
\hline Category & Critical aspects & Explanation & Excerpts \\
\hline$A$ & Extended skills & $\begin{array}{l}\text { Experiencing something new that you have not yet seen, } \\
\text { or being able to do something you have not been able to } \\
\text { do before; internalised knowledge. }\end{array}$ & $\begin{array}{l}\text { 'For me learning is to get to know something new, which } \\
\text { you have not known before and to use in task; for } \\
\text { example, facts or new ways of thinking in math'. } \\
\text { 'I think learning is when you understand how and why } \\
\text { something is as it is'. } \\
\text { 'Learning is development'. }\end{array}$ \\
\hline C & Investment & $\begin{array}{l}\text { An advantage for future challenges, such as securing } \\
\text { good employment, or having enough knowledge to live } \\
\text { independently in the future. }\end{array}$ & $\begin{array}{l}\text { 'Learning for me is that you can manage things and do } \\
\text { well in life'. } \\
\text { 'When you learn, you gather information you need in } \\
\text { the future'. } \\
\text { 'Learning is the most important thing in life, because you } \\
\text { will benefit from it in many situations'. }\end{array}$ \\
\hline D & Object & $\begin{array}{l}\text { Knowledge in the shape of an object that is acquired } \\
\text { to learn. }\end{array}$ & $\begin{array}{l}\text { 'To learn something is to gather new knowledge or } \\
\text { important information'. } \\
\text { 'Learning means you get more knowledge'. } \\
\text { 'You get new information in the brain and learn more'. }\end{array}$ \\
\hline E & $\begin{array}{l}\text { Simple casual } \\
\text { relationship }\end{array}$ & $\begin{array}{l}\text { Relationship between requirements for learning, such as } \\
\text { a teacher, memory, brain, book or Internet, that is an } \\
\text { aspect facilitating learning. }\end{array}$ & $\begin{array}{l}\text { 'You learn from your mistakes; for example, you do not } \\
\text { usually redo the same mistake again'. } \\
\text { 'It is when someone teaches someone else'. } \\
\text { 'Learning is a method of becoming well educated'. }\end{array}$ \\
\hline $\mathrm{F}$ & Attributes & $\begin{array}{l}\text { Judging what learning is, such as boring, power, funny, } \\
\text { interesting or good. }\end{array}$ & $\begin{array}{l}\text { 'I think learning is good'. } \\
\text { 'It is boring with a lot of unnecessary facts'. } \\
\text { 'I think learning is refreshing'. } \\
\text { 'Learning is boring and not funny'. }\end{array}$ \\
\hline
\end{tabular}

learning; however, only the dimensions that emerged in the empirical material were analysed here. Theoretically, the results of a variation theory analysis can be used to design patterns of variation and invariance for instruction.

If a group of students had discerned the aspects 'learner' and 'learning activities', but not considered the aspect 'outcome', the latter aspect can be made discernable. By varying different learning outcomes while keeping 'learner' and 'learning activity' the same, contrasting features of learning outcomes make this aspect discernable. These can be long-term outcomes (e.g., access to higher education or future employment), or short-term outcomes (e.g., widening knowledge). By combining different aspects and varying their features simultaneously, students can discern relationships between the learner (varying the features: skills, abilities, and pre-knowledge), the learning activity (varying the features: listening, practicing, and memorising), and learning outcomes. If a person has developed pre-knowledge (listen and practice), the probability of having a powerful learning outcome increases. This pattern of variation is called fusion (Marton, 2014). The pattern that is most powerful should be tested empirically; however, this was outside the scope of this study, as the present focus was to unveil different outcomes regarding critical aspects when analysing the same dataset from phenomenographic and variation theory perspectives. Our aim was not to test the impact of the dimensions of variation, but to analyse what dimensions of variation were opened up by the students and describe the aspects that may be theoretically critical for enhanced learning.

As an example, in Excerpt 1 below, a student opened up dimensions of the aspects outcomes and learning activity. The feature of outcomes is development, and the feature of learning activity is brain processes. To enhance this student's expressed understanding of the phenomenon (what learning is), other aspects and features have to be made discernable in suitable patterns of variation.

\section{Excerpt 1 (student 18 grade 7 ):}

To me, learning is to learn what one cannot or that one improves what one can already do. The brain also works to learn and I save what I learn if I want to learn it. Otherwise it is more difficult to learn.

A feature of the aspect outcome in Table 3 is headache. This feature was marked as 'irrelevant' because a headache may occur in all kinds of situations and is not critical for understanding the concept 'learning'. However, this aspect might be a critical irrelevant aspect for a learner in need of glasses, as reading and doing schoolwork requires sufficient vision. If the learner starts to use glasses, and no longer gets a headache when studying, it becomes obvious it was not learning that generated the headache, but poor vision. Therefore, headache is not a critical aspect in understanding what learning is.

Comparison of findings from the two approaches. The phenomenographic analysis resulted in qualitatively different categories in a hierarchical order, with the highest order including the lower orders. Participants' understanding of the concept 'learning' was sorted in a way that indicated a more differentiated and broader understanding at higher levels. The variation theory analysis resulted in identification of aspects and features relating to the concept 'learning' that were discerned by participants, with aspects not yet discerned being critical to discern for further 


\begin{tabular}{|ll|}
$\begin{array}{l}\text { Table } 3 \text { Dimensions of variation of the concept 'learning' } \\
\text { found in participants' responses }\end{array}$ \\
Aspects & Features/values \\
\hline Learner & Skills \\
& Abilities \\
& Pre-knowledge \\
& Attributes \\
Learning activities (internal/external) & Brain processes \\
& Memorising \\
& Listening \\
& Taking notes \\
& Repetition \\
& Practicing \\
& Teacher \\
& School \\
Learning sources & Friends \\
& Places/persons outside school \\
& Internet \\
& Quiz \\
& Homework \\
& Learning materials \\
& Methods \\
Forms of content/object of learning & Facts \\
(knowledge) & Information \\
& Activity \\
Outcome & Mistakes \\
& Headache \\
& Happiness \\
& Development \\
& Performance \\
& Smartness \\
& Widening knowledge \\
& Access to higher education \\
& Improved future \\
& Future employment \\
& \\
& \\
&
\end{tabular}

aFeatures defined as irrelevant to understand learning (attributes: boring, funny; headache)

development of learning. Aspects that were still to be learned were related to learners' previous discernment, but may also be related to the categories found in the phenomenographic analysis. When facilitating students to reach a higher-order category, aspects and features not yet discerned can be targeted by using the categories in a more systematic way. A person who has discerned all aspects and features has a full understanding of the concept, whereas those who have discerned fewer aspects have a limited understanding of the concept. The relationship between the outcomes is that when a person has discerned more aspects and features, their probability of experiencing a phenomenon at a higher level increases.

\section{Discussion}

This study clarified how 'critical aspects' are conceptualised differently in phenomenography and variation theory. The results from the two analyses of the same empirical dataset can be used differently. The results of the phenomenographic analysis can be used to identify different ways students' conceptualised a phenomenon, with this analysis separated from the individuals behind the sense-making. However, this information may not be directly useful to develop students' knowledge, as it focuses on the phenomenon through the perspectives of others (although this could be seen as a learning objective to strive for). The results of the variation theory analysis highlighted aspects that constituted the concept 'learning'. This provided an example of how such results could be used to enhance students' relational understanding of the objects of learning in the classroom setting, and what the teacher is trying to achieve. We do not argue that the concept 'learning' is an explicit object of learning in an ordinary classroom; however, teachers in Sweden are supposed to enhance students' generic learning skills, and assume that all students can and want to take personal responsibility for their own learning and work in school. This example was used to clarify the differences in outcome of the two analytical approaches, and show how critical aspects were used differently.

An analysis based on variation theory contributes results of subject-specific studies to design instruction that aims to enhance students' learning in specific areas (Rovio-Johansson and Ingerman, 2016), develop general skills and contribute new knowledge to understand necessary conditions for learning. Variation theory does not hierarchically arrange aspects and their features; however, the results can be used to design learning situations (Holmqvist, 2011; Holmqvist et al., 2008). Instead, variation theory implies searching for patterns of aspects and features of what is made discernable for the learner. The order of such aspects may differ between learners, and the levels of aspects and their features may be a transition of the hierarchical order used in phenomenography. This does not mean that the order of how the patterns of variation and invariance are presented is unimportant. Instead, this is of significance as beginners usually start with discerning single aspects, whereas experienced learners may use fusion to discern relationships between different aspects and features.

Important aspects may not be found in any one group of participants; therefore, it is also necessary to study the object of learning itself (first-order perspective of how the teacher discerns the object of learning) to find relevant aspects that may not have been discerned by the students. Pang and Ki (2016) called this 'the discipline-grounded way' (p. 328). Such a study is often based on research findings from previous studies. Critical aspects are used to capture the aspects of the object of learning that the learner has not yet discerned, but needs to discern to develop a deeper understanding. Some dimensions of variation that were previously opened may then be closed; for example, the conceptualisation of 'headache' as a feature of the aspect 'outcome', as it represents atypical meaning-making. Other dimensions may need to be opened for those who have not yet discerned them, making them critical for those learners to develop their knowledge further.

In all ten participating classes, we found differences between aspects that appeared to be critical. In group 8a, the main excerpts should have been placed in Category E ('Simple casual relationships'). Regarding the dimensions of variations opened, the aspects 'Learning source' (mainly the feature 'Teacher') and 'Content/object of learning' were opened simultaneously. Enhancing students' learning about the phenomenon 'learning' means trying to help them reach higher categories (A-D). To do so, the aspects not yet discerned become critical to deepen students' understanding. The analysis based on variation theory provided information about the aspects and features that can be discern in a learning situation, which links phenomenography and variation theory. The outcome from an analysis based on variation theory can be used to design teaching strategies, and ensure the teacher offers students opportunity to discern more aspects and features of the object of learning. Phenomenography and variation theory contribute new knowledge from basic research (studying the conditions for learning), and may simultaneously contribute to teachers' systematic improvement of teaching quality. The results of such analyses can also be used to predict how to design teaching activities to better meet students' needs.

We do not see a risk for phenomenography transcending into variation theory, as claimed by Åkerlind (2012). The two approaches are distinctly different, although they have the same 
origin and can contribute to each other. A living theory changes over time, and during its development, may take new directions based on new findings. The findings from phenomenographic analyses resulted in building assumptions about learning, which in turn led to variation theory. The study of what it takes to learn and theorising about the conditions resulted in conjectures possible to use for predicting how to design powerful learning situations. We think this theoretical development is a powerful example of the growth of phenomenography as a scientific approach. The two approaches should therefore not be seen as two contradicting perspectives, but rather as different approaches that unveil different kinds of knowledge about individuals' views of the world sorted in different categories (phenomenography), and how these views can be developed and changed by the use of critical aspects in a learning situation (variation theory).

\section{Data availability}

All data analysed or generated are indicated in the paper.

Received: 9 January 2019 Accepted: 17 June 2019

Published online: 09 July 2019

\section{References}

Åkerlind GS (2012) Variation and commonality in phenomenographic research methods. High Educ Res Dev 31(1):115-127

Åkerlind G (2015) From phenomenography to variation theory: a review of the development of the variation theory of learning and implications for pedagogical design in higher education. HERDSA Rev High Educ 2:5-26

Åkerlind G (2017) What future for phenomenographic research? On continuity and development in the phenomenography and variation theory research tradition. Scand J Educ Res 60(3):1-10

Boström L, Lassen LM (2006) Unraveling learning, learning styles, learning strategies and meta-cognition. Educ + Train 48(2/3):178-189

Bowden JA (2006) Phenomenographic research-some methodological issues. In: All'Alba G, Hasselgren B (eds) Reflections on phenomenography. Toward a methodology. Acta Universitatis Gothoburgensis, Gothenburg, pp. 49-66

Collier-Reed B, Ingerman $\AA$ (2013) Phenomenography: from critical aspects to knowledge claim. In: Huisman J \& Tight M (eds) Theory and method in higher education research. Emerald Group Publishing Limited, Bingley, pp. $243-260$

Duarte AM (2007) Conceptions of learning and approaches to learning in Portuguese students. High Educ 54(6):781-794

Gu L, Hunag R, Marton F (2004) Teaching with variation: a Chinese way of promoting effective mathematics learning. In: Fan L (ed.) How Chinese learn mathematics: perspectives from insiders (Vol. 1). World Scientific, New Jersey, pp. 309-347

Holmqvist M (2011) Teachers' learning in a learning study. Instr Sci 39(4):497-511

Holmqvist M, Gustavsson L, Wernberg A (2008) Variation theory-an organizing principle to guide design research in education. In: Kelly AE, Lesh R, Baek J (eds) Handbook of design research methods in education. Routledge, New York, NY, pp. 111-130

Lo ML, Pong WY, Chik PPM (2005) For each and everyone: Catering for individual differences through learning studies (Vol. 1). Hong Kong University Press, Hong Kong

Lo ML (2012) Variation theory and the improvement of teaching and learning. Acta Universitatis Gothoburgensis, Göteborg

Lo ML, Marton F (2011) Towards a science of the art of teaching: using variation theory as a guiding principle of pedagogical design. Int J Lesson Learn Stud 1 (1):7-22
Marton F (1981) Phenomenography-describing conceptions of the world around us. Instr Sci 10(2):177-200

Marton F (2014) Necessary conditions of learning. Routledge, Oxford

Marton F, Booth S (1997) Learning and awareness. Lawrence Erlbaum Associates, Mahwah, NJ

Marton F, Dall'Alba G, Beaty E (1993) Conceptions of learning. Int J Educ Res 19:277-277

Marton F, Wen Q, Wong KC (2005) 'Read a hundred times and the meaning will appear' Changes in Chinese university students' views of the temporal structure of learning. High Educ 49(3):291-318

Marton M, Pong WY (2007) On the unit of description in phenomenography. High Educ Res Dev 24(4):335-348

Marton F, Pang MF (2006) On some necessary conditions of learning. J Learn Sci 15(2):193-220

Merriam SB, Tisdell EJ (2015) Qualitative research: a guide to design and implementation. Wiley Professional Development, New York, NY

Pang MF (2003) Two faces of variation: on continuity in the phenomenographic movement. Scand J Educ Res 47(2):145-156

Pang MF, Ki WW (2016) Revisiting the idea of critical aspects. Scand J Educ Res 60 (3):323-336

Pang MF, Marton F (2005) Learning theory as teaching resource: enhancing students' understanding of economic concepts. Instr Sci 33(2):159-191

Prosser M, Trigwell K (1997) Using phenomenography in the design of programs for teachers in higher education. High Educ Res Dev 16(1):41-54

Rovio-Johansson A, Ingerman $\AA$ (2016) Continuity and development in the phenomenography and variation theory tradition. Scand J Educ Res 60 (3):257-271

Runesson U (1999) Variationens pedagogik. Skilda sätt att behandla ett matematiskt innehåll. [The pedagogy of variation. Different ways to handle a mathematical content]. University of Gothenburg, Gothenburg

The Swedish National Agency for Education (2018) Curriculum for the compulsory school, preschool class and school-age educare. Norstedts, Stockholm

Vosniadou S (ed) (2009) International handbook of research on conceptual change. Routledge, New York, NY

\section{Acknowledgements}

We thank Malmö University for supporting this study. We also thank Audrey Holmes, MA, from Edanz Group for editing a draft of this manuscript.

\section{Additional information}

Competing interests: The authors declare no competing interests.

Reprints and permission information is available online at http://www.nature.com/ reprints

Publisher's note: Springer Nature remains neutral with regard to jurisdictional claims in published maps and institutional affiliations.

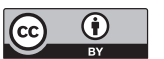

Open Access This article is licensed under a Creative Commons Attribution 4.0 International License, which permits use, sharing, adaptation, distribution and reproduction in any medium or format, as long as you give appropriate credit to the original author(s) and the source, provide a link to the Creative Commons license, and indicate if changes were made. The images or other third party material in this article are included in the article's Creative Commons license, unless indicated otherwise in a credit line to the material. If material is not included in the article's Creative Commons license and your intended use is not permitted by statutory regulation or exceeds the permitted use, you will need to obtain permission directly from the copyright holder. To view a copy of this license, visit http://creativecommons.org/ licenses/by/4.0/.

(C) The Author(s) 2019 